\title{
Infância e adolescência e redução de danos/intervenção precoce: Diretrizes para intervenção
}

\author{
Childhood and adolescence and harm reduction/precocious intervention: \\ Ways to the intervention
}

Anelize Teresinha da Silva Araújo ${ }^{[a]}$, Josiéle Cristina da Silva ${ }^{[b]}$, Fernanda Motta de Oliveira ${ }^{[c]}$

\footnotetext{
${ }^{[a]}$ Psicóloga, doutora em Psicologia Clínica pela Pontifícia Universidade Católica de São Paulo (PUC-SP), vicecoordenadora e professora do Departamento de Psicologia da Universidade Federal Fluminense (UFF), Niterói - RJ, Brasil, e-mail:

anelizetsaraujo@gmail.com

${ }^{[b]}$ Graduanda do curso de Psicologia da Universidade Federal Fluminense (UFF), bolsista de iniciação científica, Universidade Federal Fluminense (UFF), Niterói, RJ - Brasil, e-mail: josielec.silva@yahoo.com.br

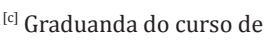
Psicologia da Universidade Federal Fluminense (UFF), estagiária de Psicologia na Rede de Saúde Mental e membro do grupo da pesquisa "A clínica com jovens e o uso de drogas", Universidade Federa Fluminense (UFF), Niterói, RJ Brasil, e-mail: femotta_uff@yahoo.com.br
}

Recebido: 09/06/2011 Received: 06/09/2011

Aprovado: 13/10//2011 Approved: 10/13/2011

\section{Resumo}

0 presente artigo visa discutir a articulação de três noções que entendemos ser de fundamental importância no que se refere ao problema do uso de álcool e outras drogas por crianças e adolescentes. Nesse sentido, será discutida a noção de violência estrutural como agente propagador da violação dos direitos da população citada; esta relacionada ao conceito de desenvolvimento no território. Em seguida, será trabalhada a introdução da noção de intervenção precoce como um modo de se alcançar a estratégia da Redução de Danos como direção de trabalho para os dispositivos assistenciais e de saúde que acolhem esse público. E, por fim, será abordada a própria estratégia da Redução de Danos e o modo como ela se insere no contexto das políticas públicas. Assim, objetivamos apresentar uma reflexão acerca de um determinado contexto - de exclusão, vulnerabilidade e desassistência - em que tais crianças e adolescentes em envolvimento com drogas estão inseridos.

Palavras-chave: Infância. Adolescente. Drogas. Redução de danos. Intervenção precoce.

\begin{abstract}
This article focuses on discussing the articulation of three concepts that we believe are of fundamental importance to the problem of alcohol and other drugs by children and adolescents. Thus, we discuss the notion of structural violence as an agent of the violation of rights of the public mentioned, which is related to the concept of development in the territory. Will introduce the concept of early intervention as a means of achieving harm reduction as a working direction for health care devices and hosting this public. Finally, we address the strategy of harm reduction and how it fits into the context of policy public. Thus, we attempt to present a reflection on a particular context - of exclusion, vulnerability and lack of assistance - like the case of children and adolescents involved with drugs are located.
\end{abstract}

Keywords: Childhood. Adolescence. Drugs. Damage reduction. Precocious intervention. 


\section{A adolescência e 0 uso de drogas: um problema}

O uso/a venda de drogas e as práticas de violência daí advindos põem questões à sociedade que necessitam ser consideradas pelas políticas públicas. Pensar sobre as motivações que levam, não só parte da população adulta, mas crianças e adolescentes a enveredarem para atividades consideradas ilícitas como uso e venda de drogas e práticas de violência pode conduzir a certo maniqueísmo caso não sejam analisados o contexto e as condições de vida contingente a cada um dos indivíduos inseridos e/ou à margem da sociedade. Inseridos porque entrar no circuito das drogas, seja pelo tráfico ou pelo uso, não deixa de ser uma maneira de inserção, e à margem porque uma atividade/trabalho ilícita está excluída da organização social institucionalmente reconhecida. Nesses termos, ao mesmo tempo em que é preciso reconhecer os modos de organização social é também preciso pensar o quanto esses modos de organização tornam-se refratários à inserção de certo número de indivíduos.

Faz-se necessário analisar o problema para que não se caia na perspectiva de entender a violência e o uso de drogas como uma "doença" inerente ao indivíduo. Como nos lembra Feffermann (2006, p. 33):

Trata-se de analisar a marginalidade não como uma manifestação psicopatológica, uma anomia, mas como manifestação do processo de desestrutura dos modelos sociais, nas suas tentativas mesmo que não patentes, de encontrar respostas às mudanças nas condições sociais e materiais.

Estamos cientes de que o problema do uso de drogas e da violência não afeta apenas uma classe social específica, mas consideramos que as condições de violência estrutural contribuem para o problema no segmento populacional com precárias condições materiais.

Considerando o segmento populacional desprovido de condições materiais básicas quer seja sob o ponto de vista de Amartya Sen (1999, p. 11), que define pobreza como "privação de capacidades", ou sob o ponto de vista dos próprios pobres, de acordo com as investigações de Crespo e Gurovitz (2002, p. 11), que a definem como:

Pobreza é fome, é falta de abrigo. Pobreza é estar doente e não poder ir ao médico. Pobreza é não poder ir à escola e não saber ler. Pobreza é não ter emprego, é temer o futuro, é viver um dia de cada vez. Pobreza é perder um filho para uma doença trazida pela água não tratada. Pobreza é falta de poder, falta de representação e liberdade.

Nesse sentido, o presente artigo será desenvolvido articulando três noções:

a) um determinado tipo de violência - a estrutural (Cruz Neto \& Moreira, 2000) - tomada como forma de violação de direitos dessa parte da população. Essa noção é um analisador fundamental para o entendimento das condições de vida da população desprovida de elementos considerados básicos à sua sobrevivência. Sejam adultos ou crianças, esse segmento populacional encontra possibilidades restritas para o desenvolvimento de modos de existência, são quase invisíveis, sem a garantia de um nome, sem história, com laços muito precários perambulando de um lugar a outro num tempo de incerteza;

b) a noção de desenvolvimento no território (Fagnani, 2011, p. 6) que diz respeito ao desenvolvimento das economias e das condições materiais de vida locais em contrapartida ao desenvolvimento econômico global;

c) para a infância e a adolescência, incluir a noção de intervenção precoce - que diz respeito à escuta clínica das queixas e problemas surgidos muito precocemente na vida das crianças -, principalmente, nas instituições primárias: os grupos familiares e as escolas.

A ação e a atenção a problemas surgidos muito cedo na vida das crianças que buscam auxílio principalmente nos Conselhos Tutelares e nos Ambulatórios Públicos ${ }^{1}$ servem de estratégia para

\footnotetext{
1 Inserindo-se nas brechas das instituições que não conseguiram servir de referência durante o percurso de desenvolvimento tanto de crianças como dos adolescentes usuários de drogas (desde a cola de sapateiro até o crack).
} 
combater e/ou amenizar os efeitos provocados pela violência estrutural e o não desenvolvimento do território. E, nos casos de alta possibilidade de vinculação (que serão abordados oportunamente), a escuta clínica, via intervenção precoce, possibilita a introdução dos indivíduos no circuito da palavra e a consequente ampliação das possibilidades do desenvolvimento dos modos de existência e de subjetivação.

Passaremos também pela concepção de redução de danos que tem sido o carro-chefe das políticas públicas para as ações relativas ao uso de álcool e outras drogas.

\section{Infância e adolescência e o uso de drogas}

Foi a partir da instauração do Estatuto da Criança e do Adolescente (ECA) que o segmento infanto-juvenil passou a ganhar visibilidade nas políticas públicas sociais. Segundo o relatório da Conferência Regional de Reforma dos Serviços de Saúde Mental de 2005, é somente em 2002, após indicações feitas na III Conferência Nacional de Saúde Mental, que o Ministério da Saúde passa a reconhecer o uso de substâncias prejudiciais à saúde (álcool e outras drogas) como um problema de Saúde Pública. A partir desse momento é que se constrói

uma política pública para a atenção às pessoas que fazem uso de álcool ou outras drogas, situada no campo da saúde mental, e tendo como estratégia a ampliação do acesso ao tratamento, a compreensão integral e dinâmica do problema, a promoção dos direitos e a abordagem de redução de danos (Brasil, 2005, p. 41).

Até então, esse serviço era realizado pela segurança pública, instituições filantrópicas e religiosas. Nesse contexto, o problema do uso de substâncias psicotrópicas por crianças e adolescentes amplia seu raio de atuação e deixa de ser apenas um problema de segurança pública para se inserir também como questão de Saúde Pública.

Como destaca Cruz Neto e Moreira (1999, p. 43), o segmento infanto-juvenil "... são extremamente dependentes de pais, irmãos, professores, médicos, condições de habitação e saneamento, ou seja, um vasto rol de pessoas, instituições que já têm sua vida e existência diretamente afetada pelas políticas públicas". De tal modo, na falha ou negligência de uma ou mais dessas instituições, uma série de agravantes podem prejudicar o desenvolvimento e as condições de vida das crianças e dos adolescentes. Por isso, se torna fundamental um trabalho alicerçado na intervenção precoce a fim de amenizar os efeitos dessas falhas que vão sendo constituídas durante o desenvolvimento dessa população.

Como afirma Cruz Neto e Moreira (1999, p. 51), em um contexto de exclusão, violência e negligência não é de admirar que os jovens de classes menos favorecidas apareçam como os propagadores da violência. "Quando se olha, porém, o 'avesso das coisas', são, antes de tudo, 'vítimas preferenciais' de uma sociedade onde a ordem de progresso é a concentração de renda e a exclusão de grupos".

A partir desse contexto e com a referida população, faz-se necessária uma diferenciação entre uso de drogas e dependência. Os usuários de drogas menores de 18 anos não são considerados toxicômanos ou drogadictos, pois, até o momento, não se pode falar em uma dependência à droga propriamente dita - apesar de, já nesse momento, a droga fazer seu efeito. A dependência não é apenas química, pois ela passa mais por aspectos da violência estrutural. Nesse contexto, o termo que melhor se encaixa nos casos de uso de drogas envolvendo jovens é "uso abusivo de drogas". Para compreender essa questão, utilizaremos a estratégia da Redução de Danos.

\section{Redução de danos: histórico}

A política de proibicionismo tem como objetivo a diminuição da oferta e da demanda de drogas, assim como a repressão e criminalização da produção, tráfico, porte e consumo de drogas. Em contraponto, as políticas públicas e programas de redução de danos para usuários de álcool e outras drogas têm disseminado intervenções orientadas para a minimização dos danos à saúde, à sociedade e à economia relacionados ao consumo de álcool e outras drogas sem necessariamente coibi-lo.

O proibicionismo está associado tanto ao modelo moral/criminal quanto ao modelo de doença que tem como finalidade explicar a questão do consumo de drogas. Para o primeiro, a solução consiste no encarceramento, uma vez que o envolvimento com as drogas é visto como um ato delituoso, enquanto o segundo prevê o tratamento como solução e a 
abstinência como principal objetivo. Nesse sentido, nenhum padrão de consumo é tolerado, não havendo distinção entre o consumo de drogas ocasional e a dependência química.

Esse modelo proibicionista, que ocorre hegemonicamente nos Estados Unidos e também é bastante influente em alguns países como Brasil, Malásia e Suécia, tem o processo de abstinência muitas vezes como um pré-requisito para o tratamento, já que não são aceitos na maioria dos programas, usuários que ainda estejam realizando algum consumo de drogas. Essa conduta pode se caracterizar como um forte obstáculo para aqueles que procuram ajuda, e também um não acolhimento por parte das instituições àqueles usuários reincidentes. Além disso, torna-se contraditório uma vez que prevê a abstinência total como pré-condição para pessoas que procuram ajuda justamente por não conseguirem se livrar do consumo da droga.

Como alternativa à hegemonia desse modelo pautado na abstinência, apostando no modelo de metas intermediárias, foram desenvolvidas em alguns países da Europa, como Holanda e Reino Unido, iniciativas que culminaram em programas de redução de danos, como afirma Cruz (2006 p. 14):

a Redução de Danos constitui uma estratégia de abordagem das questões relativas ao uso de drogas seja no âmbito do coletivo, seja no de cada indivíduo, mas que formula práticas que diminuem os danos para aqueles que usam drogas e para os grupos sociais com os quais convivem.

Essa política inicia sua consolidação nos anos 1990, tendo como foco principal a prevenção da disseminação de doenças como a AIDS e a Hepatite B entre usuários de drogas injetáveis. Na Holanda, houve uma distinção entre as drogas "pesadas", como cocaína e heroína, e as drogas "leves", como maconha e haxixe, que traziam menos riscos à saúde. Estas foram liberadas para comércio e consumo em locais específicos com o intuito de afastar o usuário do tráfico e, consequentemente, desestimular o uso das drogas consideradas mais prejudiciais ao usuário e a suas relações sociais. É importante ressaltar que as políticas de redução de danos não se opõem ao processo de abstinência, apenas não o consideram meta principal ou pré-condição para o tratamento, sendo classificado como de "baixa exigência" (Alves, 2009, p. 2313).
No programa de redução de danos, se insere a premissa de que a relação entre o homem e a droga "sempre esteve e sempre estará presente na história da humanidade" (Alves, 2009, p. 2312). A partir dessa afirmação podemos entender que o consumo de drogas não pode ser banido da sociedade e então se faz necessário que estratégias sejam utilizadas objetivando a redução dos danos causados pelo uso dessas substâncias psicoativas. Uma das alternativas encontradas na Holanda, a partir de um movimento social dos usuários, foi a disponibilização de seringas e agulhas, a fim de evitar a transmissão de doenças pelo compartilhamento desse material. Essa experiência foi bem-sucedida, uma vez que resultou na diminuição do índice de contaminação pelo vírus HIV entre os usuários de drogas injetáveis. Assim, a ideologia da política de redução de danos foi disseminada por diversos países.

Outra estratégia desse programa é a prescrição de drogas durante o processo de tratamento. Isso é entendido como uma forma de reduzir os sintomas da abstinência e gradualmente os danos relacionados ao consumo, representando também um atrativo para que o usuário tenha uma maior aderência ao tratamento.

Já na Inglaterra, o programa de redução de danos recebeu apoio da polícia, ou seja, os policiais trabalham conjuntamente com a Saúde Pública, encaminhando usuários infratores para tratamento e dando suporte aos programas de trocas de seringas. Esse programa, por sua vez, se efetivou pela articulação com a rede de farmácias, promovendo a distribuição gratuita de seringas.

Em seus primeiros anos, o processo de redução de danos provocou alguns temores que não foram confirmados ao longo do tempo, como por exemplo, o aumento deliberado do consumo de drogas. Em verdade, constatou-se um aumento na procura por tratamento por parte dos usuários atendidos pelos programas de redução e saúde em geral. No entanto, não há consenso em relação a esse assunto, e muitas vezes os motivos dessa resistência são a incompreensão de algumas premissas e a radicalidade presente nos ideais dos atores sociais envolvidos na política sobre álcool e drogas, principalmente no que diz respeito à infância e à adolescência.

No século XX, no Brasil, a repressão à venda e ao consumo de ópio e cocaína previa o regime prisional para os infratores e a "internação compulsória em estabelecimento correcional adequado por 
tempo indeterminado" (Alves, 2009, p. 2314) para os usuários, denominados toxicômanos. Entretanto, esse cenário muda na década de 1930, quando a Lei de Fiscalização de Entorpecentes, Decreto-Lei n. 891/1938 (Brasil, 1938), não distingue a penalização diante de apreensão de drogas ilícitas para consumo próprio da apreensão de drogas para o tráfico, reafirmando ainda mais o modelo proibicionista.

A Lei n. 5.726/1971 (Brasil, 1971), que dispõe medidas preventivas e repressivas ao tráfico e uso de substâncias entorpecentes ou que causem dependência, refere tratamento apenas para os considerados "infratores viciados", isto é, uma "internação em estabelecimento hospitalar para tratamento psiquiátrico pelo tempo necessário à sua recuperação" (Alves, 2009, p. 2314). Estes, por conta do vício, não teriam condições de discernir a gravidade de seu ato. As medidas tomadas nesses casos tinham caráter de reabilitação criminal do viciado e não eram consideradas questões de saúde do usuário.

Isso sofre algumas modificações a partir da Lei n. 6.368/1976, quando o tratamento no campo da Saúde passa a ser considerado para os "dependentes de substâncias entorpecentes" (Alves, 2009, p. 2314). No entanto, os princípios defendidos pela redução de danos eram tidos como indução e instigação ao uso de drogas, uma vez que uma das estratégias utilizadas é a chamada terapia de substituição, que propõe uma troca da substância da qual o indivíduo é dependente por outra que cause menores danos.

A Lei n. 6.368/1976 recomenda ainda, sempre que necessário e possível, a existência de lugares específicos da rede de saúde pública destinados ao tratamento de dependentes. Incluem-se nesse contexto serviços extra-hospitalares que poderiam ser utilizados nos casos em que a internação não fosse necessária. Porém, a criação desses serviços só foi iniciada na metade da década de 1980, fato que, muitas vezes, tornou a internação como única alternativa.

Na mesma década, foi instituído no país o Sistema Nacional de Prevenção, Fiscalização e Repressão de Entorpecentes (que posteriormente é transformado em SISNAD, Sistema Nacional Antidrogas) que, entre outros objetivos, visava formular a Política Nacional de Entorpecentes através do Conselho Federal de Entorpecentes (CONFEN). Algumas iniciativas desse órgão, marcadas por um posicionamento favorável a programas de redução de danos para usuários de drogas injetáveis, eram referentes aos centros de referência em tratamento, pesquisa e prevenção - na maioria, vinculados às universidades públicas -, e às comunidades terapêuticas - em sua maioria, não governamentais. Esse órgão foi extinto em 1998, quando foi criado um órgão normativo, o CONAD, Conselho Nacional Antidrogas, que mantém os objetivos das ações, e também um órgão executivo, a SENAD, Secretaria Nacional Antidrogas.

A partir dessas mudanças, o Ministério da Saúde passou a ser representado no CONAD pela Coordenação de Saúde Mental e também pela Vigilância Sanitária. Esse fato não extingue a posição proibicionista da legislação brasileira, mas amplia a atuação da Saúde nesse contexto. "Uma importante mudança refere-se à distinção feita entre as atividades antidrogas e aquelas de prevenção, tratamento, recuperação e reinserção social, conferindo maior destaque a estas últimas" (Alves, 2009, p. 2315).

A partir de 2002, foi decretado pela Lei n. 10.409/2002 (Brasil, 2002) que o tratamento de usuários de drogas, incluindo o núcleo familiar, fosse feito de forma multiprofissional. Isso implica em diversas formas de compreensão sobre a natureza do uso de drogas, como por exemplo aspectos biológicos, psicológicos e socioculturais, uma vez que envolve profissionais de variados campos de formação e com uma diversidade de concepções.

Essa lei contém ações referentes às políticas de redução de danos sociais e à saúde e teve vários de seus artigos vetados, não invalidando completamente a Lei n. 6368/1976 (Brasil, 1976). Evidenciando o antagonismo no contexto da política brasileira, ainda nesse ano, o Decreto n. 4.345/2002 instituiu a Política Nacional Antidrogas e caracterizou o uso indevido de drogas como uma ameaça grave à sociedade associando-o ao tráfico e à criminalidade. No entanto, também propõe que seja feita uma distinção entre a abordagem do usuário, o dependente e o traficante, fato que é bastante relevante para os direcionamentos da redução de danos, uma vez que mostra uma preocupação em garantir uma atenção especializada à saúde do usuário e do dependente.

No contexto brasileiro, as atividades de Redução de Danos surgem também, como na Europa, em políticas de prevenção diante da epidemia de transmissão do vírus HIV entre pessoas usuárias de drogas injetáveis com o apoio do Ministério da Saúde. Isso implicava, a partir de ações como distribuição de seringas individuais ou devidamente esterilizadas, 
contato com o usuário, juntamente com a oferta de tratamento tanto para o uso de drogas quanto para a saúde em geral, em uma redução dos danos provocados pelo uso da droga e não necessariamente uma interrupção no consumo. Diante disso, uma pergunta se faz importante: o que são esses danos? Segundo Pinheiro (2006, p. 27), "a noção de danos engloba ameaça à preservação da vida, dano orgânico direto, dano decorrente da dependência, dano psíquico, dano determinado pelas vias de consumo, dano decorrente das condições em que se dá esse consumo". Afirma ainda que: "A RD pode ser considerada mais como uma estratégia de intervenção do que um programa" (Pinheiro, 2006, p. 27).

Em 2002, é formulada a Política do Ministério da Saúde para Atenção Integral a Usuários de Álcool e Outras Drogas, que incluiu o SUS como responsável em garantir assistência especializada para os usuários. Está inserida nessa determinação a criação de uma rede que ofereça tratamento territorializado e esteja articulada com diversos dispositivos comunitários sociais e de Saúde, contando também com a implementação do Centro de Atenção Psicossocial Álcool e Drogas (CAPSad) . Além disso, espera-se que essa assistência esteja orientada pela política de redução de danos, garantindo aos usuários o direito à cidadania.

Devem acolher, sem julgamento, o que em cada situação, com cada usuário, é possível, o que é necessário, o que está sendo demandado, o que pode ser ofertado, o que deve ser feito, sempre estimulando a sua participação e o seu engajamento ... Aqui a abordagem da redução de danos nos oferece um caminho promissor (Pinheiro, 2006, p. 28).

Dois anos após, o CONAD aprova a Política Nacional sobre Drogas. Esta “... se orienta para a redução da oferta (ações de prevenção e repressão ao tráfico de drogas ilícitas), a redução da demanda de drogas (prevenção, tratamento, recuperação e reinserção social) e a redução de danos" (Alves, 2009, p. 2316). Nessa política, o enfoque em alcançar uma sociedade que não faça uso de drogas é substituído por outro objetivo: "uma sociedade protegida do uso de drogas ilícitas e do uso indevido de drogas lícitas" (Alves, 2009, p. 2316). Essa política também incentiva a diversidade e a coexistência de abordagens no tratamento dos usuários de álcool e outras drogas, diferentemente do Ministério da Saúde que privilegia uma política orientada pela lógica da redução de danos.

Muitas mudanças continuam ocorrendo e é possível perceber que a questão do uso de drogas passa a ser abordada de outra forma: não mais como uma ameaça, mas sim como um problema social que precisa ser considerado pelas políticas públicas. Assim, é importante lembrar que a Redução de Danos tem em suas diretrizes "pragmatismo, tolerância e respeito à diversidade" (Cruz, 2006, p. 18), ou seja, não trata a todos como se fossem iguais e tivessem a mesma relação com as drogas e mantém-se firme enquanto prática do campo de Saúde.

Além das mudanças ocorridas nos nomes dos órgãos da estrutura político-organizacional, "o Sistema Nacional Antidrogas passou a ser denominado Sistema Nacional de Políticas Públicas sobre Drogas 39; o Conselho Nacional Antidrogas, Conselho Nacional de Políticas sobre Drogas; e a Secretaria Nacional Antidrogas, Secretaria Nacional de Políticas sobre Drogas" (Alves, 2009, p. 2317), também foi criada a nova legislação brasileira sobre drogas, a Lei n. 11.343/2006, que revoga a Lei $n$. $10.409 / 2002$ e a Lei n. 6.368/1976.

Entre as modificações significativas dessa nova lei estão a possibilidade de penas alternativas para o crime de porte de drogas para uso pessoal e a transversalidade da lógica de redução de danos que entre seus objetivos tem a reorientação das ideologias do proibicionismo que ainda se encontra presente na legislação brasileira.

\section{Violência estrutural e intervenção precoce}

Segundo Cruz Neto e Moreira (1999, p. 35), o Estado é "responsável direto pelo estabelecimento das condições de vida de uma população. Direitos básicos dos indivíduos como os acessos à alimentação, educação e saúde são por ele influenciados, definidos e implementados". Assim, ao gastar "bilhões de reais em políticas que privilegiam grupos restritos..., o Estado vitimiza o resto da população, infligindo-lhe violências como a fome, a miséria e a exclusão social..." (Cruz Neto \& Moreira, 1999, p. 35). Constata-se que a violência estrutural atinge toda a população; embora diretamente direcionada ao segmento menos favorecido da sociedade, não deixa de produzir efeitos em toda a sociedade. 
Podemos compreender, então, a violência estrutural como uma defasagem na estrutura que cerceia parte da sociedade e restringe-lhe o acesso, por direito, a bens e serviços básicos. Assim, nas comunidades em que estão alocadas as populações menos favorecidas, e que não recebem a atenção do governo quanto à melhoria das condições de vida dessa população, o tráfico, na figura do traficante, muitas vezes, cumpre um papel que deveria ser de responsabilidade do Estado. Como nos mostra Amorim (2003, p. 35) e é de domínio público:

0 crime organizado ocupa as lacunas de assistência social que o Estado vai deixando para trás, ao sabor da crise econômica ou da insensibilidade política. A dominação sobre as comunidades pobres passa quase que necessariamente por esse tipo de estratégia, até porque o bandido mora na favela e é mais permeável às reivindicações do morador. ... A marginalização produz esse fenômeno social, ético e político.

Vale ressaltar que o interesse aqui não é avaliar se é mérito do tráfico dar assistência à população, até porque é preciso pensar a que custo isso se torna possível, mas dar visibilidade a determinado tipo de fato que ocorre quando o Estado negligencia um segmento específico da sociedade.

Buscando meios para sair de uma condição, por vezes, degradante, de descaso e desassistência, a população recorre a diversos meios: trabalhando como camelô, vendedor ambulante, lavando e tomando conta de carros, trabalhando para o tráfico etc. Os jovens são as principais vítimas desse descaso, posto que necessitam ajudar no orçamento da família, ou mesmo porque são impelidos a consumir produtos que a mídia divulga, inclusive drogas. Para isso, precisam trabalhar; e para trabalhar, talvez, precisem deixar de estudar; e deixando de estudar, diminuem suas chances de ascender socialmente ou, ao menos, melhorar suas condições de vida. E, assim, esse círculo se propaga. É nesse contexto que o tráfico de drogas se constitui como uma das poucas chances para que esses jovens consigam uma posição de inserção na sociedade, visto que o montante de dinheiro que o jovem ganha nessa atividade costuma ser maior do que em outro trabalho no mercado formal.

Expor determinada população a essas condições não ocorre sem motivo: a vulnerabilidade à qual essa população está exposta apresenta-se como barganha para jogos de poder (seja da política, da igreja, do tráfico de drogas, da mídia etc.). A vulnerabilidade social que a violência estrutural promove

Constitui-se em um indicador das frustrações, desrespeito e privações que a sociedade impõe a determinados cidadãos sinalizando para ela que a interação e a acumulação dessas situações vão ao longo da existência individual e do processo histórico, deteriorando as condições de vida de extensos segmentos populacionais (Cruz Neto \& Moreira, 2000, p. 28).

O quadro de ineficácia de grande parte dessas políticas que envolvem a camada mais pobre da população os afeta diretamente e de forma mais grave, posto que:

Não possuem recursos para procurar instituições privadas que supram a rarefação pública: educação, saúde, lazer, habitação, renda, condições de salubridade ... o acesso a esses direitos é cerceado e até mesmo negado a um grande contingente de cidadãos que assistem à dramática redução de suas oportunidades de ascensão social, sendo obrigados a viver sob condições indignas e de extrema vulnerabilidade (Moreira, 2000, p. 29).

Tal configuração corrobora toda uma prática de violência estrutural que já, ao não assegurar a toda população o acesso a bens e serviços e condições de vida dignas, limita o leque de escolhas da população menos favorecida, levando-a a optar pela mendicância, tráfico de drogas, crime em diversos casos.

É de fundamental importância ressaltar que:

... o fato desses adolescentes serem tradicionais vítimas da violência estrutural não estabelece uma relação determinista, que explicaria por si só e univocamente sua entrada para o tráfico de drogas. 0 que se pretende demonstrar é que a baixa qualidade de vida e a dramática restrição de possibilidades cria neles uma instabilidade psíquica, física, material, e social que associada às incertezas, dúvidas e reações de rebeldia típicas de seu momento etário psicológico, deixa-os mais vulneráveis à interferência daqueles que tencionam aproveitar-se de seus problemas ... (Moreira, 2000, p. 30). 
Com a sanção da Lei n. 8.069, de 13 de julho de 1990, o ECA foi promulgado e a infância e a adolescência passaram a ter maior visibilidade dentro da sociedade com uma lei que prevê proteção integral. Para assegurar o cumprimento dessa lei, elege-se os conselheiros tutelares, escolhidos mediante eleição direta.

De acordo com o artigo 227 da Constituição Federal brasileira:

É dever da família, da sociedade e do Estado assegurar à criança, ao adolescente e ao jovem, com absoluta prioridade, o direito à vida, à saúde, à alimentação, à educação, ao lazer, à profissionalização, à cultura, à dignidade, ao respeito, à liberdade e à convivência familiar e comunitária, além de colocá-los a salvo de toda forma de negligência, discriminação, exploração, violência, crueldade e opressão (Brasil, 1988).

Nesses termos, e a partir do que foi abordado até aqui, observamos que tais direitos das crianças e adolescentes não têm sido cumpridos em muitos casos, trazendo um peso difícil de suportar. Muitas vezes, a família não consegue ou não tem condições de dar a assistência necessária, visto que ela própria não recebe nenhum tipo de assistência do Estado.

Assim, entender a violência estrutural como forma de violação de direitos não só das crianças e dos adolescentes, mas também dessa população desassistida aponta a necessidade de uma estratégia de trabalho voltada para a redução de danos no sentido de pensar a intervenção precoce. Isso porque, ao considerar esses jovens usuários de álcool e outras drogas - principalmente, o crack - como violadores de direitos, é preciso lembrar que em sua trajetória de vida eles tiveram grande parte de seus direitos violados em um momento muito anterior. Nesses termos, pensar redução de danos para crianças e adolescentes torna-se mais complexo, pois tal tarefa não se restringe à distribuição de insumos; além disso, sua aplicação esbarra no proibicionismo presente nas leis e nos moralismos presentes na sociedade em geral.

Pensando nisso, a proposta da redução de danos para essa população seria um trabalho voltado para a intervenção precoce, ou seja, uma intervenção que se dê antes do período crítico possibilitando-lhe um lugar para que possa avançar na consolidação de sua subjetivação.
O trabalho da intervenção precoce também prevê grandes desafios. É preciso certo cuidado para que não se estigmatize os jovens logo que cheguem aos dispositivos que os assistem. Porém, é preciso estar atento aos indícios que vão se apresentando e se delineando, e às especificidades de cada caso, bem como os traços recorrentes que podem ser úteis na formulação de estratégias e alternativas ao caminho dramático que pode vir a se apresentar. Assim, pode-se dizer que a estratégia de intervenção precoce propõe não um trabalho alicerçado na proibição, mas na escuta clínica social quando do aparecimento do problema.

A estratégia de redução de danos e a de intervenção precoce é também um modo de buscar amenizar os prejuízos causados pela violência estrutural, bem como pela violação de direitos que tais jovens sofrem pelas instituições que deveriam cuidar deles.

\section{Intervenção precoce nas situações de alta, média e baixa possibilidade de vinculação}

A título de conceituação operacional, diferenciaremos os tipos de caso relacionados ao uso de drogas em alta, média e baixa possibilidade de vinculação.

A alta possibilidade de vinculação engloba os casos de jovens que chegam aos dispositivos de assistência social, saúde mental ou conselhos tutelares, espontaneamente ou levados pela família, solicitando tratamento para uso de drogas e que conseguem manter seus vínculos sociais. Nesses casos, o uso de drogas é apenas mais um elemento do caso e a problemática nomeada de "risco social" está ligada, principalmente, a problemas referidos à adolescência e a seu contexto sociocultural.

Os casos de média possibilidade de vinculação abarcam jovens que conseguem realizar algum pedido de ajuda decorrente dos danos físicos e sociais provocados pelo uso de drogas. Eles não chegam por meios próprios aos dispositivos da Saúde ou da Assistência Social, sendo levados pelas equipes de Abordagem de Rua do CREAS, famílias ou PMF, entretanto permanecem vinculados aos serviços para os quais foram encaminhados ou frequentando de maneira irregular. Geralmente, encontram-se em risco de vida em razão do envolvimento com o tráfico. Em tais casos, a questão da droga é o mediador 
social entre as relações existentes, mas seu uso não é o que verdadeiramente os coloca em risco.

Na baixa possibilidade de vinculação encontram-se os jovens que estão em risco social e de vida decorrente do uso de drogas e do envolvimento com o tráfico. Muitos são expulsos de suas comunidades e chegam aos Conselhos Tutelares e às Casas de Passagem levados por terceiros; não conseguem permanecer em tais dispositivos por períodos maiores que uma ou duas semanas. Alguns também traçam seu percurso pela Justiça através de medidas de Liberdade Assistida ou semiliberdade. Possuem suporte familiar frágil e permanecem a maior parte do tempo vivendo pelas ruas da cidade. Nesses casos, o risco de vida é diretamente ligado ao uso compulsivo da droga.

Assim, na categorização proposta, fica explícita a diferenciação relativa ao uso de drogas na categoria de alta possibilidade de vinculação, em que esse uso está associado à adolescência e a seu contexto sociocultural, e na categoria baixa possibilidade de vinculação, em que há risco de vida diretamente ligado ao uso compulsivo da droga. Nos casos de alta possibilidade de vinculação, o tratamento faz-se mais efetivo porque a droga é utilizada no sentido de dar suporte aos problemas do contexto da adolescência.

O grau de possibilidade de vinculação de cada caso delimita também o tipo de intervenção a ser feita. Nesse sentido, a redução de danos é realizada justamente no intervalo entre o uso, buscando introduzir outro objeto além da droga, ou seja, é uma tentativa de deslizamento do objeto "droga", tirando o foco desta. A intervenção precoce - principalmente, executada pelos agentes dos programas de medicina de família e pelos ambulatórios públicos, considerando que tais agentes estão organicamente inseridos no território - se torna o recurso para o desenvolvimento dos processos subjetivos e para a escuta daqueles precocemente envolvidos em sofrimento psíquico.

\section{Considerações finais}

A partir do caminho traçado até aqui, constata-se que a inserção de jovens usuários de drogas no tráfico não está alicerçada apenas numa condição individual que denuncia uma questão psicopatológica, mas antes numa ineficiência, numa dificuldade das diversas instituições que perpassam a vida desses jovens e da população em geral, tais como a família, a escola, o exercício das leis, a falta de acesso etc.

Tendo em vista a noção de violência estrutural apresentada, é possível articulá-la com a questão da violação de direitos, posto que é preciso considerar que, antes de violadores de direitos, os jovens usuários de álcool e outras drogas, em muito casos, são sujeitos que tiveram seus direitos violados em uma ou diversas situações anteriores.

Os casos de adolescentes usuários de crack e outras drogas deslocam-se do lugar de um problema de Segurança Pública - em que a punição não dá conta do problema - para situar-se como problema de Saúde Pública. Porém, não se pode perder de vista que esse é um problema que pede o envolvimento de diversos segmentos que assistem esse público. Nesses termos, o combate à violência estrutural depende da intervenção do Estado no desenvolvimento socioeconômico cultural do território.

Nesse contexto, pensar redução de danos com jovens e crianças deve caminhar na direção de se fazer a intervenção antes do período crítico - intervenção precoce. Para a efetivação de tal proposta, faz-se necessário que, de fato, haja uma articulação entre os segmentos que atravessam a vida dessa população (educação, família, assistência social, saúde, justiça etc.). A mais efetiva redução de danos com crianças e adolescentes se dará quando houver uma reforma na estrutura dos meios aos quais essa população tem acesso e no desenvolvimento do território no qual essa população está inserida.

\section{Referências}

Alves, V. S. (2009). Modelos de atenção à saúde de usuários de álcool e outras drogas: Discursos políticos, saberes e práticas. Caderno de Saúde Pública, 25(11), 23092319. doi:10.1590/S0102-311X2009001100002.

Amorim, C. (2003). CV e PCC a irmandade do crime. Rio de Janeiro: Record.

Brasil. (1938). Decreto-Lei n. 891, de 25 de novembro de 1938. Aprova a Lei de fiscalização de entorpecentes. Diário Oficial [da] República Federativa do Brasil. Brasília, DF. Recuperado em 16 jan. 2013, de https://www.planalto.gov.br/ccivil_03/decreto-lei/1937-1946/del0891.htm 
Brasil. (1971). Lei n. 5.726, de 29 de outubro de 1971. Dispõe sobre medidas preventivas e repressivas ao tráfico e uso de substâncias entorpecentes ou que determinem dependência física ou psíquica e dá outras providências. Diário Oficial [da] República Federativa do Brasil. Recuperado em 16 jan. 2013, de http://www010.dataprev.gov.br/sislex/paginas/42/1971/5726.htm

Brasil. (1976). Lei n. 6.368, de 21 de outubro de 1976. Dispõe sobre medidas de prevenção e repressão ao tráfico ilícito e uso indevido de substâncias entorpecentes ou que determinem dependência física ou psíquica, e dá outras providências. Diário Oficial [da] República Federativa do Brasil. Brasília, DF. Recuperado em 16 jan. 2013, de http://www010.dataprev.gov.br/ sislex/paginas/42/1976/6368.htm

Brasil. (1988). Constituição (1988). Constituição da República Federativa do Brasil. Brasília, DF: Senado Federal.

Brasil. (1990). Lei n. 8.069, de 13 julho de 1990. Dispõe sobre o Estatuto da Criança e do Adolescente e dá outras providências. Diário Oficial [da] República Federativa do Brasil. Brasília, DF. Recuperado em 26 maio 2011, de https://www.planalto.gov.br/ccivil_03/leis/18069.htm

Brasil. (2002). Lei n. 10.409, de 11 de janeiro de 2002. Dispõe sobre a prevenção, o tratamento, a fiscalização, o controle e a repressão à produção, ao uso e ao tráfico ilícitos de produtos, substâncias ou drogas ilícitas que causem dependência física ou psíquica, assim elencados pelo Ministério da Saúde, e dá outras providências. Diário Oficial [da] República Federativa do Brasil. Brasília, DF. Recuperado em 16 jan. 2013, de http://www.planalto.gov.br/ccivil_03/ Leis/2002/L10409.htm

Brasil. (2005). Ministério da Saúde. Coordenação Geral de Saúde Mental. Reforma psiquiátrica e política de saúde mental no Brasil. Documento apresentado à Conferência Regional de Reforma dos Serviços de Saúde Mental: 15 anos depois de Caracas. Brasília, DF.
Brasil. (2006). Lei n. 11.343, de 23 de agosto de 2006. Institui o Sistema Nacional de Políticas Públicas sobre Drogas - Sisnad. Diário Oficial [da] República Federativa do Brasil. Brasília, DF. Recuperado em 17 jan. 2013, de http://www.planalto.gov.br/ccivil_03/_ ato2004-2006/2006/lei/l11343.htm

Crespo, A. P., \& Gurovitz, E. (2002). A Pobreza como fenômeno multidimensional. RAE-eletrônica, 1(2), 1-12. doi:10.1590/S1676-56482002000200003.

Cruz, M. S. (2006). Considerações sobre possíveis razões para a resistência às estratégias de redução de danos. In O. Cirino \& R. Medeiros (Org.). Álcool e outras drogas: Escolhas, impasses e saídas possíveis. (pp. 13-24). Belo Horizonte: Autêntica. PMCid:1569831.

Cruz Neto O., \& Moreira M. R. (1999). A concretização de políticas públicas em direção à prevenção da violência estrutural. Ciência saúde coletiva, 4(1), 33-52. doi:10.1590/S1413-81231999000100004.

Fagnani, E. (2011). Como conquistar o desenvolvimento social. Lê Monde Diplomatique - Brasil, 6-7.

Feffermann, M. (2006). Vidas arriscadas: $O$ cotidiano dos jovens trabalhadores do tráfico. Petrópolis, RJ: Vozes.

Moreira, M. R. (2000). Nem soldados nem inocentes: Jovens e tráfico de drogas no município Rio de Janeiro. Dissertação, Mestrado em Saúde Pública, Fundação Oswaldo Cruz, Rio de Janeiro.

Pinheiro, R. M. (2006). Redução de danos e psicanálise aplicadas à toxicomania. In 0 . Cirino, \& R. Medeiros (Org.). Álcool e outras drogas: Escolhas, impasses e saídas possíveis. (pp. 25-31). Belo Horizonte: Autêntica.

Sen, A. (1999). Desenvolvimento como liberdade. São Paulo: Companhia das Letras. 